\title{
EMBRACING INFORMATION AS CONCEPT AND PRACTICE
}

\author{
Robert Stephens \\ University of the West of England
}

\begin{abstract}
In this position paper it is argued that generic theories of the information concept will be an obstacle to the Information Systems discipline assuming intellectual leadership of the information portfolio associated with the growth of computing technologies beyond the organization.
\end{abstract}

Keywords: Information, information systems

The information systems discipline embraces information both as concept and as practice. A convention has been to place the concept information on a continuum between data and knowledge or wisdom (e.g., Avison and Fitzgerald 2003, p. 17; Walsham 2001, p. 36). The practice has been defined by the expansion of computing technologies within the business and corporate sectors. Information systems (IS) were variously categorized as transaction systems, management information systems, and intelligent support systems, and serviced business or organizational needs. Although problematic and contestable, the notion of information and systems could be referenced against a framework of organizational requirements giving the scope of IS practice a relatively stable focus. The contemporary growth of inter-organizational systems and the penetration of digital computing devices throughout society compromises this reference background, as does the promise of an information society. Because of this, what can be considered information and what belongs within the IS practitioners' remit is no longer defined solely by organizational requirements.

In this position paper, it will be argued that the emergence of genuinely plural horizons for IS presents both an opportunity and a threat to an IS discipline. Because the IS research community is uniquely positioned between technical and social worlds and their reciprocal interactions, it should be providing intellectual leadership on an inclusive discourse about the functions of information within the society at large, including business. By embracing this opportunity, an IS discipline can prevent a fragmentation 
of information studies into exclusive fields, and distinguish itself from cognate fields, such as management and computing. The challenge of an inclusive grasp of the information portfolio may be accompanied by a threat to conceptual coherence, which will be felt particularly keenly in education, where disciplinary authorities are expected to supply theoretical guidance on core concepts. However, providing a theoretical platform for IS education and practice in the shape of generic theories of information is likely to compromise the inclusive mandate to take seriously the nature of information as a practical achievement.

The contemporary form of information is highly heterogeneous. It is said to reside in molecules, cells, tissues, genes, minds, libraries, the environment, the economy, organizations, societies, all sorts of systems, and so on. We can be information rich, empowered, poor, or saturated, experience information revolutions and ages, be information analysts, scientists, workers, and managers, who have information requirements and needs. Information itself can be auditory, visual, tactile, and electronic, which may be precise, poor, candid, secure, public or private, dishonest or mischievous. In fact the limits to information appear to reside less in the environment itself and more in digital technologies and techniques themselves, and in the ingenuity of information architects. Novel technologies such as RFID (radio frequency identification) will no doubt yield novel information categories, as will the convergence of better established fields such as biometric and actuarial information. In short, the notion of information and of systems will not longer be contained by the narrow work and decision processes of organizations, but will relate to wider social and economic concerns.

Among those who work in the information industries, it is generally held to be an open scandal that there is no theory, or even definition, of information that is both broad enough and precise enough to accommodate the above uses of the word in a meaningful way. With respect to technology, many also regret the contribution such a theory could make to the design and construction of information systems, which, despite a seeming ubiquity, have made a distinctly uneven contribution to either business or society (e.g., Seely Brown and Duguid 2000; Willcocks and Lester 1999). Further, a requirement for clarity over information is likely to be more keenly felt as IS moves its concerns from information structures to information content (Willcocks and Lester 1999), interoperability, and convergence, and from the storage and manipulation of information to the qualities and characteristics of that information itself. These trends are already apparent with the arrival of ontologies (Castel 2002; Guarino 1995), the semantic Web (Bemers-Lee 1999), and supporting technologies such as XML, and with the shift in concern from the medium (machines, networks, etc.) to the message (software, decoded DNA sequences, digital identity, etc.).

In an academic context, the theoretical deficit may be inhibiting an understanding of the role such systems play in a wider context, the development of a core IS curriculum in education, and a closer collaboration of researchers and practitioners. Further, if information systems as an academic discipline had its own distinct subject matter which included a robust definition of information, then it would be better equipped to defend itself from cognate, but predatory, emerging fields such as bioinformatics or new media, as well as the more established reference fields of management, computing and information science. 
However, the information concept has been notoriously resistant to analytical resolution. Everything can be made to seem obvious, but very little is. Dictionaries assume it rather than explain it (Hobart and Schiffman 1998), and etymologies fail to be more precise. Within the information systems field, many have sought to approach analytical clarification, but explanations are notoriously circular and self-referential. Elsewhere I have used the philosophical argument supplied by Wittgenstein (1953) to demonstrate such a theoretical attitude should be resisted because information appears first as a conceptual term (Stephens 2001). Further, such a theory would form a barrier rather than a contribution to understanding and leave IS as a discipline with a highly stylized but inappropriately idealized and impractical subject matter.

Information Systems students are taught to distinguish information from data and knowledge, and sometimes wisdom, but considering our ever-expanding expectations from the term, we are not used to thinking any more critically about information. Agre (1995) notes that "the term 'information' rarely evokes the deep and troubling questions of epistemology that are usually associated with terms like 'knowledge' and 'belief."' One can be a skeptic about knowledge but not about information (Nunberg 1996, p. 107). Indeed, the term appears epistemologically normative, and we are encouraged to take information for granted. Thus IS has hitherto concerned itself with information form, leaving content to other professionals, or merely taking it as given, unproblematically read off the world.

Where the IS remit is extended to working across organizational boundaries, or where formal organizations don't exist at all, the IS practitioner will need to assume responsibility for information content. Information systems work will increasingly be concerned with the assimilation and synthesis of diverse sources of information and knowledge as work and other activities become informated along heterogeneous networks (cf. Castells 1996) rather than managed hierarchical paths. Moreover, the scope of the information concept will need to be revised as a complex phenomena embracing such issues as propriety, regulation, ethics, accessibility, and even aesthetics.

As a consequence, the disciplinary substrate of IS will need to meet this diversity, or risk a subject fragmentation that would leave much of the world of digital applications beyond IS theorizing and IS academic and professional authority. Such an expansion will also demand a new type of competence from the IS practitioner. Mastery of theory and of technical and methodological means will be subsumed by (not replaced by) the ability to engage in rule-making and identifying goals appropriate to particular information and knowledge practices. This entails a shift from a bureaucratic to a charismatic personality (Gray 2001) and in many ways the IS professionals' job description will have significant parallels with the architect or designer. These tasks involve reworking the situated materials of everyday life, reconnecting the local obligations and commitments of the everyday world to the more abstract processes of public life. The new orientation will, therefore, entail the discipline and flair of information design on the one hand to a renaissance attitude to professional conduct on the other.

In this paper, I have tried to suggest that the rapid diffusion of information and information technologies through diverse areas of human endeavor will require information systems practitioners, academics, and students to consider information content closely. A generic theory of information will at best offer disengagement from the unknown and obstruct the learning processes that are essential features of IS 
development, much in the way methodologies can (Wastell 1996). Many IS topics will lack clear authorities, and contextual ambiguity and open-endedness relativizes theoretical studies, so the need is to review problems from a number of perspectives. To engage actively with rich information content and knowledge requires of the IS professional, first, a versatility of character and, second, a literacy, or mastery of competing information genres.

Further, academics need to recognize the historically contingent nature of what is the product of a complex of social and technological processes. Recent scholarship on the codex book (Johns 1998) and cartography (Wood 1992) demonstrates that the actually contested nature of artifacts is easily concealed by a totalizing discourse when persuasive institutions conspire to reify and naturalize their products. Both of these examples are particularly instructive for information systems, for the establishment of such intellective artifacts provides the starting point of another process whereby these very products have the appearance of a window through which the world is seen. To reveal the nature of the phenomenon, it is necessary to examine the practices of those who use information.

Ignoring the processes of production would be an intellectual denial and leave the field open to sociologists, science studies scholars, etc., who have a limited technical understanding of the information field and are inclined to pursue their own academic agendas. It would also cripple the IS discipline pedagogically because it would direct intellectual scrutiny away from the essentially practical tasks facing students and professionals-i.e., the labor and craft of information design. Moreover, unless IS researchers become an active voice within the discourse addressing information content, the discipline will be increasingly challenged for its relevance by other academic fields that are rapidly embracing digital technology. Because IS research community is uniquely positioned between technical and social worlds and their reciprocal interactions, it should be able to provide intellectual leadership by locating itself at the center of this discourse.

The information systems discipline must articulate information both as concept and practice, but this cannot be achieved exclusively. The terms are mutually referential, reflexive, and thereby unresolvable by a universal or generic theory. In fact, the problems of sense and reference surrounding conceptual terms such as information are now integral to working practice because, as Zuboff (1989) and others have argued, digital technology creates a context where work becomes an ensemble of readings, inferences, and interpretations. Conceptual issues are not detachable from empirical ones. They are there whenever a question arises about what counts as information, about how to interpret information, about what theoretical or practical inferences to draw, and how to proceed. To delegate responsibility for conceptual issues to a given theory of information would be to deny what much information work is really about: the intellectual, social, and tactile spadework or articulation work (Suchman 1996) that crafts ambiguity and openness into interpretively tractable working situations. For IS professionals, who are ipso facto mandated to intervene in others' lives, such circumscribed theorizing can only be an obstacle to the authentic insights required for ethical and practical action (Stephens and Probert 2000). 


\section{REFERENCES}

Agre, P. E. "Institutional Circuitry: Thinking About the Forms and Uses of Information," Information Technology and Libraries (14:4), 1995, pp. 225-230.

Avison, D., and Fitzgerald, G. Information Systems Development: Methodologies, Techniques and Tools, Maidenhead, UK: McGraw-Hill, 2003.

Berners-Lee, T., and Fischetti, M. Weaving the Web: The Original Design and Ultimate Destiny of the World Wide Web by Its Inventor, San Francisco: Harper, 2000.

Castel, F. "Ontological Computing," Communications of the ACM (45:2), 2002, pp. 29-30.

Castells, M. The Information Age: Economy, Society and Culture, Volume 1: The Rise of the Network Society, Malden, MA: Blackwell, 1996.

Gray, J. "The End of Career," Communications of the ACM(44:11), 2001, pp. 65-69.

Guarino, N. "Formal Ontology, Conceptual Analysis and Knowledge Representation," International Journal of Human-Computer Studies (42), 1995, pp. 625-640.

Hobart, M. E., and Schiffman, Z. S. Information Ages: Literacy, Numeracy and the Computer Revolution, Baltimore, MD: John Hopkins University Press, 1998.

Johns, A. The Nature of the Book: Print and Knowledge in the Making, London: University of Chicago Press, 1998

Nunberg, G. The Future of the Book, Berkeley: University of California Press, 1996.

Seely Brown, J., and Duguid, P. The Social Life of Information, Boston: Harvard Business School Press, 2000.

Stephens, R. A. "Problems with a Theoretical Attitude to the Information Concept,"in D. Strong and D. Straub (Eds.), Proceedings of the $7^{\text {th }}$ Americas Conference on Information Systems, Boston, 2001, pp. 1963-1967.

Stephens, R. A. and Probert, S. K. "Authentic Intervention in Information Systems Practice," in H. R. Hansen, M. Bichler, and H. Mahrer (Eds.), Proceedings of the European Conference on Information Systems, Vienna, July 2000, pp. 64-70.

Suchman, L. A. "Supporting Articulation Work," in R Kling (Ed.), Computerization and Controversy: Value Conflicts and Social Choices ( $2^{\text {nd }} \mathrm{ed}$.), San Diego: Academic Press, 1996, pp. 407-423.

Walsham, G. Making a World of Difference: IT in a Global Context, Chichester, UK: Wiley, 2001.

Wastell, D. G. "The Fetish of Technique: Methodology as a Social Defence," Information Systems Journal (6), 1995, pp. 25-40.

Willcocks, L. P., and Lester, S. (Eds.). Beyond the IT Productivity Paradox, Chichester, UK: Wiley, 1996.

Wittgenstein, L. Philosophical Investigations, trans. G. E. M. Anscombe, Oxford: Blackwell, 1953.

Wood, D. The Power of Maps, London: Routledge, 1992.

Zuboff, S. In the Age of the Smart Machine: The Future of Work and Power, Oxford: Heinemann, 1989.

\section{ABOUT THE AUTHOR}

Robert Stephens is senior lecturer in information systems in the School of Information Systems, University of the West of England. He holds a Ph.D. in information systems and researches the evolution of computing and information systems in society, particularly with respect to the dialogic theory ofM. M. Bakhtin. He can be reached at Robert.Stephens@uwe.ac.uk. 